\title{
Nurse communication in health education: Patients' perspective
}

\author{
Azza Fathi Ibrahim *1, Faiza Mohammed Tawfik², Dalal T. Akel ${ }^{3}$ \\ ${ }^{1}$ Nursing Education Departement, Faculty of Nursing, Alexandriea University, Egypt \\ ${ }^{2}$ Medical Surgical Nursing Department, Faculty of Nursing, Alexandria University, Egypt \\ ${ }^{3}$ Nursing Administration Department, Faculty of Nursing, Ain Shams University, Egypt
}

Received: April 27, 2015

DOI: $10.5430 /$ cns.v3n4p94
Accepted: August 25, 2015

URL: http://dx.doi.org/10.5430/cns.v3n4p94

\begin{abstract}
Although nurses have accepted health education as an important role, they are not practicing it in a consistent and structured manner. Several factors have been proposed as an explanation for the discrepancy between expectation and practice of nurses in health education, with ineffective communication being the first. The nurse as a health educator should have appropriate interviewing and communication skills to convey health messages. Nurse should be able to communicate information that helps patients to discover: future or present health problems; more satisfying personal meaning; description about growth and development stages; how to accept or resolve conflict feeling, how to be more creative and become more oriented by self and circumstances. Therefore, this is an exploratory descriptive study, aimed at identifying the perception of patients on nurses' communication during health education. A convenient sample was obtained comprised of 238 patients in medical sections: 100 from Gamal Abd El Naser Hospital and 138 from El Amery University Hospital; both in Alexandria, Egypt. The Health Communication Feedback questionnaire (HCFQ) was used to collect the necessary data. The study revealed that patients at medical section who with chronic medical diseases; generally have a significantly positive perception regarding nurses' communication during health education. Such as: they detected some problems that nurses encountered in this communication; these problems may be in patient him/herself as $46.2 \%$ of subjects having pain and can't mutually interact with nurse in health education, or unable to understand nurse's information. In relation to the problems that detected in nurses as perceived by study subjects, lacking of nurse' time and limitation in communication skills. In health settings, the most apparent problems were insufficient facilities or materials for patient teaching and excessive interruptions and crowding. For the perceived problems in relation to health messages, about $45 \%$ of patients found jargons in nurses' health messages and $27 \%$ of them reported that messages were not attractive or interesting enough. Furthermore, results showed that there is no specific relation between the nature of patients' chronic disease and their perception regarding nurse communication during health education. Conclusion: This study highlighted the importance of patients' views for modifying and improving health professionals' performance, which are utilized to provide guidelines and directions to develop better nurses' communication outcomes in health education. Observing, examining and identifying these perceptions will provide recognition and vision for future effective nurse-patient interactions in the health education paradigm.
\end{abstract}

Key Words: Health education, Communication, Perception, Nurse, Patient

*Correspondence: Azza Fathi Ibrahim; Email: azza_fathy2008@yahoo.com; Address: Alexandriea University, Faculty of Nursing, Nursing Education Departement, Egypt. 


\section{INTRODUCTION}

Health education plays a central role in health promotion: maintenance, restoration, changing, encouraging, ensuring, persuading or modifying patients' health behaviors. Therefore, it is a science which emphasizes the developing of individual's thinking capacities, self-care decision making and recognition of values related to health and illness. It provides an excellent chance for educational, motivational, skill-building and informed autonomous healthy decisions for patients. ${ }^{[1,2]}$

Nurses as health educators should communicate health messages effectively with patients, family and society aspiring to optimal wellbeing. Health care professionals should be aware with updated knowledge and oriented by the educational, communicational, and social processes in establishing health education intervention. Nurse-client communication is built upon warmth, trust, empathy, and mutual respect. The client must believe that the nurse cares, understands, and is concerned about his or her problem. A caring and safe environment helps the nurse embrace and value the client's internal and external experience, strengthen shared decision making, elicit relevant clinical data, and formulate individualized care. As well, nurses should be able to apply the health education process: assessment, planning, implementation, evaluation and documentation, an integrated and ongoing process, with a total plan for patient care. ${ }^{[3-5]}$

According to several researches, nurse communicative behaviors seem to be important in meeting the cognitive and the affective needs of patients. These include instrumental behaviors, which are significant in informing the patient about illness, treatment, medical and practical care as well as showing respect, and providing comfort and trust which are important in building a good relationship with the patient. ${ }^{[6,7]}$

Patients are the mirrors for nurses' performance, particularly, patients who deal with nurses for a long time as whom with long term illness. Moreover, many researchers reported that the most common cases that need urgent and continuous health education are those who with chronic diseases such as diabetes, hypertension, liver cirrhosis and cancer. In these conditions, patients need to develop a range of competencies that allow them to take greater control of self care management. Health messages are intended to provide them an opportunity to learn selected information and skills for prolonged self care maintenance. Consequently, health communication is a valuable nursing intervention for this group of patients. ${ }^{[1,8,9]}$

Successful communication by health care professionals is the key for effective health education but there is still a struggle in how to manage it productively and there is a prevalent dilemma faced by hospitals and other health care settings about a theoretical and practical gap in communication competencies for nurses as health educators. ${ }^{[10-12]}$

Abd El Mohsen A. in 2009 mentioned that nurses have minimal preparation and training to conduct appropriate communication with patients and families. Fathy in 2006 reported that nurses give health teaching without applying scientific principles of communication and there are several barriers which provoked uneasiness during nurse-patient interactions. ${ }^{[1,3]}$ As well, Kotb H. in 2015 recommended that health personnel should obtain confidence and competence during patient communication to ensure transfer of health messages. ${ }^{[13]}$ All previous authors did their studies in Egypt, which clarified: there is a big problem in nurses' health communication but they neglected to investigate this problem from patients' perspectives. Therefore, the aim of the current study is to explore and identify patients' views regarding nurses' communication during health education, which has very obvious implications for educational intervention in health care services. Investigating patients' views concerning this issue will be a great step for re-establishing and improving the health education role in nursing. This paper is considered unique in studying the communication of nurses during health education activity from patients' perspectives.

\section{Research questions}

(1) What are the patients' perceptions regarding the nurses' communications during health education?

(2) What are the problems that confronted by nurses to communicate effectively in health education as perceived by patients?

(3) Does the disease nature affect patients' perceptions as regards nurses' communication in health education?

\section{MeTHODS}

\subsection{Settings and sampling}

An exploratory, descriptive design is used in three medical sections at Gamal Abd El Naser Hospital and three other medical sections at El Amery University Hospital in Alexandria, Egypt. Official permission and approval to conduct the study was received from the authorities of the mentioned settings and confidentiality of the subjects was assured by anonymity. The minimum sample size of 200 was determined using the Fishers' formula $\mathrm{z}^{2} \mathrm{pq} / \mathrm{d}^{2}$. A convenience sample was used including 238 patients who have medical diagnoses with eligible settled criteria. Then, they were selected by a stratified proportionate sampling between the six medical sections from both mentioned hospitals; 100 from the first hospital and 138 from the second one. The eligible criteria for participation were: patients from both sexes, having an 
established chronic medical diagnosis as a major diagnosis, able to read and write, a minimum age of 18 and a maximum of 60 years old, alert, able to communicate, receiving health education from nurses during hospitalization and willing to participate in the study by signing a written consent. Patients were asked to fill in a self administered questionnaire in the presence of the researchers to clarify any vague questions.

\subsection{Study tool}

The Health Communication Feedback questionnaire (HCFQ) was developed by Yorkshire Cancer Network in 2006 ${ }^{[14]}$ to determine patients' feedback about nurse communication. Tool was adopted, modified and translated in Arabic by Fathy A. in $2011^{[10]}$ to determine patients' evaluation and feedback on student nurses' communication. In current study this tool modified to investigate nurses' communication particularly in health education from patient perspectives. This tool includes a Likert Scale that consists 24 equally positive and negative statements with a 5 point response: strongly disagree $=1$, disagree $=2$, not sure $=3$, agree $=4$, and strongly agree $=5$. Total score is 120 ; from 24 to 40 were represented low and negative score, from 41 to 80 indicated neutral score and from 81 to 120 represented positive and high score for patient feedback on nurses' communication in health education. The statements are in relation to nurses' attention, clarity of language, non verbal expression, respect and confidence ... etc. In addition, sociodemographic data is included. This tool was adopted and modified by the researchers. Four questions were added to explore the problems that nurses encountered in health communication from patients' perspectives according to a review of related literature. ${ }^{[1,6,15]}$ Then the tool was submitted to a jury of seven experts in nursing education, medical surgical nursing and health education fields to ensure tool content validity. Reliability was measured using the Cronbach Alpha Reliability Test with values ranging from 0.66 to 0.72 . A pilot study was carried out on seventeen patients, separate from the study sample, to test tool clarity, feasibility, time needed to fill and understanding of its items. Subsequently, necessary modifications were done.

\subsection{Data analysis}

Data was fed, coded, edited and analyzed using a PC with Statistical Packages for Social Science (SPSS, 19), Version 7.0 for Windows. The selected level of significance was $p$ $\leq .05$. The results were estimated using numbers, percentage, and arithmetic mean and standard deviation. Analytical statistics were done using T-Test.

\section{Results}

Table 1 shows that the majority of the respondents (57\%) were in their fiftieth. As well, about two thirds (61.34\%) were male. Approximately one half of them (45\%) were married. In addition, most of them $(79.4 \%)$ came from rural areas. About half of the patients $(49.6 \%)$ had primary and preparatory education while more than one third $(36.9 \%)$ were workers. Moreover, more than one half of them $(22.69 \%$ plus $29.4 \%$ ) had liver and heart diseases.

Table 1. Percent distribution of the subjects according to their general characteristics

\begin{tabular}{|c|c|c|}
\hline \multirow{2}{*}{ Personal characteristics } & \multicolumn{2}{|c|}{ Total $(n=238)$} \\
\hline & $\mathbf{N}$ & $\%$ \\
\hline \multicolumn{3}{|l|}{ Age } \\
\hline $20 \leq 35$ & 62 & 26.1 \\
\hline $35 \leq 45$ & 28 & 11.8 \\
\hline $45 \leq 50$ & 12 & 5.0 \\
\hline $50 \leq 60$ & 136 & 57.1 \\
\hline \multicolumn{3}{|l|}{ Sex } \\
\hline Male & 146 & 61.34 \\
\hline Female & 92 & 38.56 \\
\hline \multicolumn{3}{|l|}{ Marital status } \\
\hline Married & 107 & 45.0 \\
\hline Single & 42 & 17.6 \\
\hline Divorce & 32 & 13.4 \\
\hline Widow & 57 & 23.9 \\
\hline \multicolumn{3}{|l|}{ Residence } \\
\hline Urban & 49 & 20.6 \\
\hline Rural & 189 & 79.4 \\
\hline \multicolumn{3}{|l|}{ Level of education } \\
\hline Read \& write & 12 & 5.0 \\
\hline Primary \& preparatory & 118 & 49.6 \\
\hline Secondary & 106 & 44.5 \\
\hline High education & 2 & 8.0 \\
\hline \multicolumn{3}{|l|}{ Occupation } \\
\hline Worker & 88 & 36.97 \\
\hline Employee & 25 & 15.9 \\
\hline Farmer & 53 & 33.8 \\
\hline Retirement & 42 & 26.7 \\
\hline Unemployed & 30 & 19.1 \\
\hline \multicolumn{3}{|l|}{ Medical diagnosis } \\
\hline Liver disease & 54 & 22.69 \\
\hline Heart disease & 70 & 29.4 \\
\hline Renal failure & 28 & 11.8 \\
\hline Diabetes Mellitus & 42 & 17.7 \\
\hline Respiratory disease & 44 & 18.49 \\
\hline
\end{tabular}

Respectively, the first study question may be answered by the data in Table 2 which represents the patients' perceptions of nurse communication in health education. Generally, almost all items have a mean of more than 3.00 with a $p$ value 
$\leq .05$ which are statistically significant for the total items. Additionally by some investigations, both gender categories Correspondingly, the majority of the male and female study have approximately equal means for negative or positive subjects have a positive perception globally for whole scale views, but with statistically significant differences in nine points concerning nurse communication in health education. items of the scale.

Table 2. Distribution of the study subjects according to their perceptions regarding nurses-patient communication during health education as related to gender

\begin{tabular}{|c|c|c|c|c|c|c|}
\hline \multirow{2}{*}{ Nurses' communication activities in health education } & \multicolumn{2}{|c|}{ Males $(n=146)$} & \multicolumn{2}{|c|}{ Females $(n=92)$} & \multirow{2}{*}{ T-Value } & \multirow{2}{*}{$p$ Value } \\
\hline & Mean & SD & Mean & SD & & \\
\hline 1 Greets and shows interest in me as a person & 4.38 & 0.69 & 4.12 & 0.84 & 2.60 & $.01^{*}$ \\
\hline 2 Teaches by words that show care $\&$ calming & 3.66 & 1.20 & 3.33 & 0.94 & 2.24 & $.026^{*}$ \\
\hline 3 Uses tone, pace, and posture that shows care and concern & 3.65 & 1.32 & 3.94 & 0.88 & 1.86 & .064 \\
\hline 4 Makes efforts to put me at ease $\&$ decrease fear or anxiety & 3.43 & 0.90 & 3.54 & 0.68 & 1.01 & .316 \\
\hline 5 Encourages asking questions \& feedback with confidence & 4.49 & 0.63 & 4.13 & 0.72 & 4.06 & $.0001^{*}$ \\
\hline 6 Communicates without attention, motivation or eye contact & 2.84 & 0.91 & 2.35 & 0.89 & 4.08 & $.0001^{*}$ \\
\hline 7 Gives information in a clear and understandable manner & 3.43 & 0.90 & 3.12 & 0.90 & 2.59 & $.010^{*}$ \\
\hline 8 Considered a non trustworthy source of information & 2.38 & 1.22 & 2.66 & 1.54 & 1.56 & .121 \\
\hline 9 Speaks in a rapid hasty way & 1.75 & 1.44 & 2.11 & 1.23 & 1.98 & $.048^{*}$ \\
\hline 10 Asks about feelings as well as physical health & 3.79 & 1.20 & 3.75 & 1.44 & 0.23 & .817 \\
\hline 11 Speaks in an open, attractive $\&$ honest manner & .844 & 0.91 & 4.67 & 0.97 & 1.37 & .173 \\
\hline 12 Uses helpful instructional aides effectively & 2.60 & 0.49 & 2.45 & 1.11 & 1.43 & .155 \\
\hline 13 Gives superficial information or skills without goals & 4.35 & 0.59 & 4.27 & 0.87 & 0.85 & .399 \\
\hline 14 Uses verbal and non verbal communication & 3.65 & 1.35 & 3.45 & 1.36 & 1.11 & .268 \\
\hline 15 Neglects to check for mutual understanding & 4.25 & 0.76 & 4.39 & 0.63 & 1.48 & .141 \\
\hline 16 Intends to avoid any discussion or listening to me & 4.26 & 0.91 & 4.22 & 0.76 & 0.35 & .726 \\
\hline 17 Helps me in important decisions \& provides alternatives & 4.07 & 0.97 & .344 & 0.93 & 2.12 & $.035^{*}$ \\
\hline 18 Speaks to me in hesitant and interrupted speech & 3.43 & 0.90 & 3.29 & 1.43 & 0.93 & .355 \\
\hline 19 Neglects to speak about my emotions or opinions & 3.75 & 1.44 & 3.44 & 1.31 & 1.67 & .096 \\
\hline 20 Unable to meet my health education needs. & 2.35 & 0.66 & 2.23 & 0.73 & 1.31 & .191 \\
\hline 21 Provides enough time to explain $\&$ discuss my concerns & 3.22 & 1.72 & 3.55 & 0.89 & 1.70 & .090 \\
\hline 22 Discourages me to express my own ideas & 1.64 & 0.98 & 1.75 & 1.44 & 0.70 & .484 \\
\hline 23 Gives details with jargon \& sophisticated data & 3.75 & 0.66 & 3.33 & 0.92 & 4.09 & $.0001^{*}$ \\
\hline 24 Unable to use clarifications or examples & 4.77 & 0.97 & 4.56 & 0.91 & 4.04 & $.0001^{*}$ \\
\hline Total & 3.36 & 0.98 & 3.43 & 0.90 & 0.55 & .580 \\
\hline
\end{tabular}

${ }^{*}$ Significant relation at $p$ level $\leq .05$

By excluding items No. 6, 8, 9, 12, 20 and 22, for both sexes, it is clear that all items have a mean of more than 3.00 which indicates positive perceptions. Item No. 11, speaks in a manner that was open, attractive \& honest, occupied the 1 st rank with a mean $=4.84,4.47$ for male and female patients. Item No. 24, unable to use clarifications or examples, occupied the 2 nd rank with a mean $=4.77,4.56$ among both sexes.

It was observed that male and female patients agree on two opposite views; first, in items 1, 5, and 17 that a nurse greets and shows interest in a patient as a person, encourages feedback and helps in taking decisions and second, in items 13 and 16 that a nurse gives superficial information and intends to avoid any discussion or listening.

In relation to items No. $6,8,9,12$ and 22 having a mean of less than 3.00 for both male and female patients, these denote disagreement; that the nurse communicates without attention, is considered a non trustworthy source of information, speaks in a rapid hasty way, uses helpful instructional aides effectively and discourages to express ideas, and, unable to meet their education needs.

Concerning the second study question, it may be answered by Table 3 which represents the problems encountered by the nurses' communication as perceived by study patients.

Regarding perceived problems in patients themselves, about half of study subjects $(46.22 \%)$ perceived that pain is the most common problem disturbing nurse-patient communication, and $35.71 \%$ of them mentioned that they have misunderstandings frequently with nurses. In relation to perceived 
problems in the nurses, about one third of the study subjects (29.41\% and $27.31 \%$ ) perceived that nurses have limited time for health teaching and lacked communication skills.

Table 3. Distribution of the study subjects according to the perceived problems that hinder nurse-patient communication during health communication

\begin{tabular}{|c|c|c|}
\hline Problems perceived by patients & $N=238$ & $\%$ \\
\hline \multicolumn{3}{|l|}{${ }^{*}$ Problems in patient him/herself } \\
\hline Poor concentration & 50 & 21.00 \\
\hline Rejects nurse as a source of teaching & 15 & 6.30 \\
\hline No trust of knowledge or skills & 50 & 21.00 \\
\hline Misunderstanding & 85 & 35.71 \\
\hline \multicolumn{3}{|l|}{ Common patient symptoms that hinder education: } \\
\hline Pain & 110 & 46.22 \\
\hline Vomiting & 25 & 10.5 \\
\hline Psychological condition & 35 & 14.71 \\
\hline Headache & 65 & 27.31 \\
\hline Anxiety & 50 & 21.00 \\
\hline Cough & 15 & 6.3 \\
\hline \multicolumn{3}{|l|}{ *Problems in nurse himself/herself } \\
\hline Lack of information in health education & 35 & 14.71 \\
\hline Lack of communication skills & 65 & 27.31 \\
\hline Embarrassment in providing certain topics & 20 & 8.4 \\
\hline Lack of time for health teaching & 70 & 29.41 \\
\hline Inability to use audiovisuals in health teaching & 30 & 12.6 \\
\hline \multicolumn{3}{|l|}{ *Problems in health setting } \\
\hline Uncooperative hospital staff & 50 & 21.00 \\
\hline Unsuitable venue & 15 & 6.3 \\
\hline Insufficient facilities or materials & 90 & 37.82 \\
\hline Excessive interruptions \& crowding & 85 & 35.71 \\
\hline \multicolumn{3}{|l|}{ "Problems in health messages } \\
\hline Message is not related to health condition & 16 & 6.72 \\
\hline Message is vague and not understood & 24 & 10.08 \\
\hline Message is not attractive or interesting & 65 & 27.31 \\
\hline Message includes jargon & 108 & 45.38 \\
\hline
\end{tabular}

* Each patient has a chance to give more than one response

The apparent perceived problems in relation to the health setting, more than one third $(37.82 \%$ and $35.71 \%)$ of patients reported that there are insufficient facilities or materials for patient teaching and there are excessive interruptions and crowding in the hospital as a health education venue. For the perceived problems in relation to health messages, nearly one half of the subjects $(45.38 \%)$ stated that they are frequently receiving health messages with jargon. One third (27.31\%) of them mentioned that health messages from nurses were not attractive or interesting enough for them to comply.

To answer the third study question, it is obvious in Figure 1 that there is no difference between patients' diagnoses and their perceived communication from the nurse. The majority of all patients with different diagnoses have positive perception.

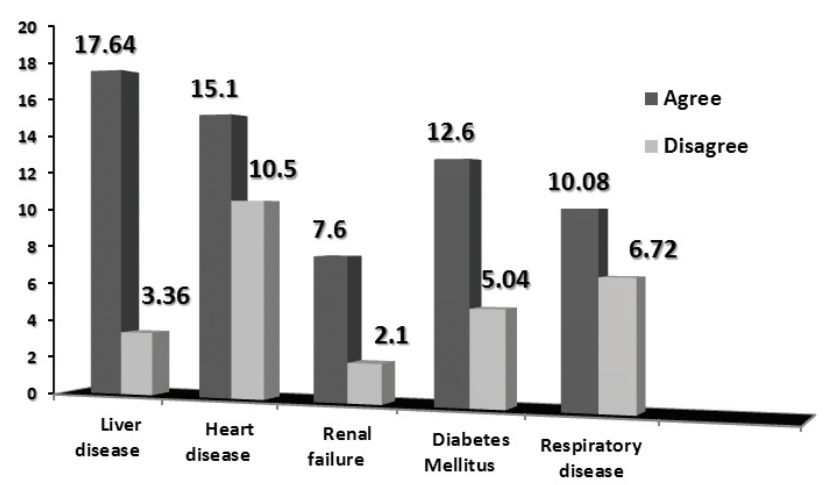

Figure 1. Distribution of subjects according to their diagnoses and perception about nurse-patient communication

Agree $=$ agree + strongly agree $;$ Disagree $=$ disagree + strongly disagree

Patients with liver cirrhosis have the greatest positive perception of $17.64 \%$ among all chronic conditions. However, patients with heart disease have the greatest negative perception of $10.5 \%$. On the other hand, patients with renal failure have the lowest positive and negative perception percents $(7.6 \%, 2.1 \%)$ among all medical diagnoses of the study subjects.

\section{Discussion}

Health education activities should enhance the active involvement of patients to become collaborators in their health care process. The strong relation between patients and health professionals points to a high level of patient independency. ${ }^{[16]}$ Nurse-patient communication involves supplying of information. It also entails transmitting feelings, attitudes, values and personality cues either verbally or nonverbally that evidently affect patient understanding and compliance to health information. ${ }^{[9,17]}$ Health outcomes can be affected extensively by the quality of communication between health professionals and patients. When nurses pay attention to patient complaints, understand his/her needs and problems, focus on helpful care, provide guidance and conduct health teaching, patient health improves by a meaning of "proximal outcomes of the interaction" e.g., satisfaction with care, motivation to adhere and trust in the clinician and system. ${ }^{[4,18]}$

This study focuses on the patients' perspectives about nursepatient communication, particularly in health education which is exceptional as there are very minimal studies in 
this track. First of all, the study revealed that in general both male and female patients have a positive perception concerning nurses' communication during health education. This was not expected in Egypt because there are numerous factors affecting nursing in Egypt such as: shortage of staff, work burden, public view, low salaries and time restraints which may affect nursing communication and her/his manner in patient teaching. Rashdan T (2007) supported this point of view when discussing that there are multiple difficulties that weaken the advancement of professional nursing activities in Egypt which sequentially may inhibit goal acquisition including supply and demand for nurses, educational level of nurses, long work hours, working conditions and low wages. ${ }^{[19]}$ Egypt suffers from a severe shortage in the number of nurses in hospitals and public clinics. There are 276 nurses for every 100,000 people. This is documented in the United Nations Development Program and The Institute of National Planning, Egypt, 2005. [10,19]

The majority of both gender categories of study subjects perceived that nurses speak in a manner that was open, attractive and honest. However, they were unable to use clarifications or examples. These perceptions came in the first and second patients' ranking for both sexes for positive views. The first one may be because patients are seeing nurses as the main sources of support and the only person staying with him/her for a long period. While for the second perception, it can be justified that nurses have a limited time to give examples or clarifications. Congruent with patients' perceptions, Macdonald L, et al. (2013) $)^{[18]}$ reported that nurses should have the upper hand in health consultation with flexibility and humanity. While many nurses were qualified in practical aspects, they were yet to use an appropriate manner for explanation and degree of familiarity with conducting patients' consultations. Additionally, in Egypt, Abd El Mohsen A, 2009 ${ }^{[1]}$ illustrated that although the nurse in health communication is a trustworthy source of help, he/she still lacked in the art of explanation and conversation. Moreover, Collins R. 2014 discussed that nurses must not only be present physically for patients, but they must also assure them, with full awareness and active communication. ${ }^{[20]}$

Male and female subjects in the present study saw that nurses greet and show interest in a patient as a person, encourage feedback and help him/her in taking decisions. However, nurses give superficial information and intend to avoid any discussion or listening. This clarifies that nurses interact with patients in an effective and respectful manner except in handling essential health education skills. Similar to this perception, Levin M. in 2006 discussed that health professionals possibly have low confidence in exercising teaching skills such as listening, that can result in a failure to pro- vide effective patient health education. ${ }^{[7]}$ Besides, in Egypt, Fathy A. in 2006 concluded that the nurse as a health educator may have insufficient teaching knowledge or skills, and health education loses its effectiveness, while interpersonal and social skills are successful. ${ }^{[3]}$ On the other hand, Berkman N, et al. in 2010 mentioned that the clever nurse is competent in the following health education skills: reading and understanding written text, locating and interpreting information in documents, writing or completing forms, and speaking and listening effectively. ${ }^{[21]}$ As well, the World Health Organization in 2003 described that patient education and counseling with health professionals represents the state of the art of education; not only conversation about general health requirements for potential users of health care, but also including patient rights and ethical issues, behavioral means, techniques of communication and teaching, learning methodologies and informational technology. ${ }^{[3,22]}$

Although, both male and female patients selected and gave agreement for negative statements, they also were in favor of nurses. Patients disagreed that nurses communicate without attention, are considered a non-trustworthy source of information, speak in a rapid hasty way, discourage the expression of ideas and are unable to meet their education needs. Of course, patients view are mostly right because nurses should have caring activities during health communication such as providing attention, encouraging mutual understanding, speaking with suitable pacing and attentiveness to patient demands. In the same line which support patients' disagreement with any nurse' negative activities in health communication, the College of Nurses of Ontario in 2013 reported that the nurse establishes and maintains the key relationship with clients by using caring attitudes and behaviors. Therapeutic nursing services contribute to the client's health and well-being. The relationship is based on trust, respect, empathy and professional intimacy, and requires appropriate use of the power inherent in the care provider's role. ${ }^{[23]}$ Furthermore, nurses are obligated to provide health care physical activities, such as bathing, eating, and giving medications, which construct closeness and professional intimacy with psychological, spiritual and social elements that are identified in the plan of care. ${ }^{[24]}$ Congruently, with effective nurse-patient communication, the nurses must be aware of how they appear to the client. If a nurse appears rushed, speaks quickly, breaths heavily, with eyes not focused on the client but perhaps on an intravenous bag or on the client in the next bed, this of course breaks communication and enhances patient frustration. ${ }^{[10,15]}$

Patients in the current study, have negative views regarding the effectiveness of the use of helpful instructional aides among nurses. Yet, nurses are not prepared to be health ed- 
ucators as mentioned above. This perception is supported in Egypt by Fathy A. in $2011^{[10]}$ who clarifies that there is an inadequacy in the educational training for nurses in the field of health education, particularly in using instructional aids, perhaps due to a deficiency in clinical experiences in this field. The production of high quality audiovisual materials for patients, along with the informed and skillful use of them, is an important aspect for the health educator which is limited in Egyptian nurses. Similarly, inability to prepare, select and develop instructional aides for patients is considered a great barrier for communicating health messages and requires attention from nursing education. ${ }^{[1,10]}$ Dissimilar to these points of views, the key role of the professional nurse is tailoring effective patient and family education which includes selecting the right educational materials and making sure that they are age-specific, clear, easy to use, accessible and appropriate to patient needs. The preparation of these materials requires talent and skills which are basic to nursing work. ${ }^{[2]}$

In relation to the difficulties that affect nurses in communicating effectively in health education as perceived by patients, regarding difficulties in patient themselves, they found that their pain is the major problem that disturbed the nursepatient communication. Congruent with their view, Awasthi SH. and Bhandari M. in 2006 reported that each individual has a different capacity to learn and varying dimensions of physical, emotional, and cognitive readiness. When a patient suffers from acute symptoms such as pain, vomiting, coughing or dyspnea, he/she is not ready for learning. In addition to that, a patient's readiness for learning is very important data to be assessed in the health educational process to ensure patient comfort, concentration and alertness for learning. ${ }^{[3,25]}$

Other difficulty perceived in patients themselves is that they have frequent misunderstandings with nurses. So, nurses confront several problems when interpreting patients' learning needs. This can be due to different cultures, beliefs, norms and personalities. Parallel to this view, in Egypt, Oueda M. in 1999 discussed that the way of thinking differs from one patient to another. Health beliefs and cultures affect the person when seeking health care services as a result of understanding the importance of health or severity of illness. Misunderstandings are expected and the nurse should give a great attention to these variables in planning for education. ${ }^{[3,26]}$ Dissimilar to this analysis, Abd El Mohsen A in 2009 recommended that the nurse should bridge all difficulties and barriers in health education by careful listening and learning the art of communication. ${ }^{[1,10]}$ Additionally, Leininger M. and McFarland R. in 2006 reported that transcultural nursing care is a critical skill of the nurse which improves adherence to the treatment plan, reduces recidivism, and decreases overall costs for health care. ${ }^{[27]}$

Concerning the difficulties in nurses themselves, patients saw that nurses have no time to communicate with them and conduct proper health education. In support of this perception, time constraints and the lack of well-defined role expectations for health education are frequently cited by nurses as barriers to provide effective health communication. ${ }^{[3,20]}$

Moreover, in this aspect, patients perceive that nurses have limited communication skills. Matching this view, Levin M. in 2006 explained that health professionals have an apparent decrease in communication skills that negatively affect patient interactions. ${ }^{[7]}$ On the other hand, in Egypt, and dissimilar to this explanation, Fathy A, in 2011 reported that communication skills are the subtle skills of the nurses and if they missed them, patient needs will not be met and health problems cannot be resolved. ${ }^{[10]}$

The obvious perceived problems by study subjects, in relation to the health setting which is that there are insufficient facilities or materials for health communication and there are excessive interruptions and crowding in the hospital. It is expected complains from patients regarding any health setting. In line with this insight, Valley H, in 2003 mentioned that the lack of adequate materials, resources and policies in health communication are apparent problems in this field. Almost all nurses consistently provide verbal information to patients without a specific time, materials or a special place. ${ }^{[3,28]}$ Moreover, Taha E., in 1999 stated that there are several factors unconstructively affecting patient education in hospitals; mainly that there is no suitable place for patient teaching and also the unavailability of equipment, facilities and instructional aides to be used in teaching sessions. ${ }^{[29]}$ As well, Collins R. in 2014 concluded that to increase patient satisfaction and drive growth and loyalty, healthcare facilities must be committed to provide humanized, high quality nursing care through effective nurse-patient communication processes. ${ }^{[20]}$

In relation to patients' perceived problems regarding health messages, they are frequently receiving health messages with jargon and they are not attracted or interested. Harmonious with this point, Abdel Mohsen A. in 2009 stated that health messages may not be comprehended by patients for several reasons including; non-interest, preoccupation, fatigue, mood changes or messages that included jargon. Nurses should provide some effort to overcome these barriers. ${ }^{[1,6]}$ On the other hand, preparation of specific health messages should elicit the desired patient behavior as well as grasp their attention. Health communication messages need to be focused on real concerns and not diluted with extraneous data. 
Information messages should be short, powerful, attractive and clear.

The last revealed result was detected that there is no specific relation between a patient's diagnosis and the perceived health communication from the nurse. Evidently, the majority of all patients with different chronic diseases have positive perceptions. Cooper H C., et al., in 2003 illustrated that without any doubt, communication is predetermined and consistent with all health or illness conditions. It should be customized continuously to be permanently the key of patient and nurse interactions. ${ }^{[30]}$ Contradicting to this finding, Visser A. in 2001 clarified that health education with a chronic disease receives growing attention; in particular with diabetic patients as this is a well developed area. Therefore, the nature of the disease affects development of patient education. Each chronic disease has explicit particular health education content, materials and strategies. ${ }^{[31]}$ Similar to this line, Clinical Innovation and Governance, Family and Community Services, in 2014 reported that it is important when supporting people with a disability to note that there may be challenges in developing and maintaining communication and behavioral support on a daily basis. ${ }^{[32,33]}$ This can be particularly evident when supporting people with complex communication and behavioral challenges. Health staff should have read and understood the Nursing and Health Care Communication and Behavior Core Standard which is urgently needed in nursing curricula.

Hence, nurse-patient communication in the health education process should involve the client and the nurse in an interactive process of empathic understanding regardless of any other variables such as culture, education and the nature of the disease. Through this process, the meaning of experiences is shared, resulting in mutual understanding of the associated affective and behavioral outcomes.

\section{Conclusion}

This study is incomparable because it is the first to report on patients' perceptions toward nurses' communication in health education in Egypt, which concluded that patients with chronic illness generally have positive perceptions. Accordingly, we can say the view of nurses is changing towards the positive side. There are some problems hindering effective nurse communication as perceived by patients such as; physical complaints like pain, limited time and communication skills particularly in health teaching among nurses, limited facilities or materials for patient teaching and excessive interruptions and crowded health settings. Finally, the health messages of nurses include jargon and do not attract or interest patients thus negatively affecting compliance. These findings indicate that in congruent to the literature, nurses are not good at communication with patients and lacked communication skills with the exception of obtaining positive perceptions from patients with chronic illness regarding their communication in health education.

\section{Recommendation and further studies}

This study recommends conducting further studies on the perception of patients with chronic illnesses in different regions of Egypt or Arabian countries. More investigations are required in barriers to the health educator role, particularly regarding health settings. It is urgent to develop and implement in-service training programs in governmental and nongovernmental hospitals in Egypt regarding effective communication predominantly in health education. Nursing curricula should include a health education subject for clinical and theoretical aspects. Therefore, a survey ought to be conducted in all faculties of nursing in Egypt to determine the coverage of health education content in nursing curricula.

\section{REFERENCES}

[1] Abd El Mohsen A. Barriers Encountered by Undergraduate Nursing Students While Providing Health Education for Patients. Unpublished Master Thesis. Faculty of Nursing, University of Alexandria; 2009. 34-12 p.

[2] World Health Organization. Regional Office for the Eastern Mediterranean. Health Education: Theoretical Concepts, Effective Strategies and Core Competencies, a Foundation Document to Guide Capacity Development of Health Educators. 2012.

[3] Fathy A. Development of Patient Health Education Model to Guide Undergraduate Nursing Students. Unpublished MSN Thesis. Alexandria: University of Alexandria, Faculty of Nursing; 2006. 23-37 p.

[4] Hartman E. Role of the Professional Nurse Regarding Patient Education. Practice and Research Program. NYSNA's Council on Nursing
Practice. 2006.

[5] McCabe C, Timmins F. Communication Skills for Nursing Practice. Palgrave MacMillan. 2006.

[6] Kruijver I, Kerkstra A, Bensing J, et al. Communication Skills of Nurses during Interactions with Simulated Cancer Patients. Journal of Advanced Nursing. 2001; 34(6): 772-7. PMID:11422547. http://dx.doi.org/10.1046/j.1365-2648.2001.01807.x

[7] Levin M. Language as a Barrier to Care for Xhosa-Speaking Patients at a South African Pediatric Teaching Hospital. S Afr Med J. 2006 Oct; 96(10): 1076-9.

[8] Shuldham C. A review of the Impact of Pre-operative Education on Recovery from Surgery. International Journal of Nursing Studies. 1999; 36: 171-177. http://dx.doi.org/10.1016/S0020-748 9 (99) 00010-3 
[9] Wright R. Effective Communication Skills for the "Caring" Nurse. Pearson Education. 2012.

[10] Fathy A. Effect of Role-Play versus Lecture Teaching Strategies on Nursing Students' Communication Skills during Patient Education. Unpublished PHD Thesis. Alexandria: University of Alexandria, Faculty of Nursing; 2011. 32-55 p.

[11] Spiegel W, Zidek T, Maier M. Breaking Bad News to Cancer Patients: Survey and Analysis. Psycho-Oncology. 2009; 18: 179-186. PMID:18677710. http://dx.doi.org/10.1002/pon.1383

[12] Bach S, Grant A. Communication and Interpersonal Skills for Nurses. Learning Matters Ltd; 2009.

[13] Kotb H, Flory T. Sex and the Married Muslim Education. Salon Media Group. 2015.

[14] Yorkshire Cancer Network. Assessing and Improving Communication in Cancer Services. 2006.

[15] Prasad VC, George S. Effectiveness of Structured Teaching Module on Therapeutic Communication among staff nurses. Journal of Nursing and Health Science. 2014; 3(2): 27-31. http://dx. doi .org/1 $0.9790 / 1959-03212731$

[16] Otong D. Nurse-Client Communication: A life Span Approach. London, Jones and Bartlett publishers; 2007. 3-15, 22-3, 56-18 p.

[17] McCabe C. Nurse-Patient Communication: an Exploration of Patients' Experiences. Journal of Clinical Nursing. 2003; 13: 41-49. http://dx.doi.org/10.1111/j.1365-2702.2004.00817.x

[18] Macdonald L, Stubbe M, Tester R, et al. Nurse-Patient Communication in Primary Care Diabetes Management: An Exploratory study. Bio Med Central Nursing Ltd. 2013; 12-20.

[19] Rashdan T. Implications for Advancement of Egyptian Nursing: Input equals Output. Doha, White Paper for Fulbright Academy Workshop 2007.

[20] Collins R. Best Practices for Integrating Technology into Nurse Communication Processes; Technology can Close Communication Gaps that Separate Nurses from Patients and Families. American Nurse Today. 2014; 31-32. PMID:25742348. http://dx.doi.org/10. 1097/01.NAJ.0000451680.81694.07
[21] Berkman N, Terry D, McCormack L. Health literacy: what is it? J Health Comm. 2010; 15: 9-19. PMID:20845189. http: //dx.doi.org/10.1080/10810730.2010.499985

[22] World health organization. Study Group. Effective Teaching: A guide of Educating Health Care Providers: USA. JHPIEGO. 2003: 85-111.

[23] College of Nurses of Ontario. Practice Standard: Therapeutic NurseClient Relationship. College of Nurses of Ontario. 2013.

[24] Kunyk D, Olson JK. Clarification of the Conceptualizations of Empathy. Journal of Advanced Nursing. 2003; 5(3): 317-325. http: //dx.doi.org/10.1046/j.1365-2648.2001.01848.x

[25] Awasthi SH, Bhandari M. Identification and Prioritization of Barriers to Quality Performance in Medical Education and Patient Care. Medical University in India, Kamla-Raj. 2006; 13(2): 157-162.

[26] Oueda M. Analytical Review for Models Related to Health Education. Faculty of Nursing, University of Alexandria. 1999; 1-8, 13-35.

[27] Leininger M, McFarland R. Culture Care Diversity and Universality a Worldwide Nursing Theory. 2nd ed. Boston, MA: Jones and Bartlett Publishers; 2006.

[28] Valley H. Nurses Identify Barriers to Teaching Patients about Their Medications. Institute for Safe Medication Practices. 2003.

[29] Taha E. A study for Developing Visual Educational Materials for Low Literate Adult Diabetics. MSN thesis, Faculty of Nursing, University of Alexandria. 1999; 13-6.

[30] Cooper HC, Booth K, Gill G. Patients' Perspectives on Diabetes Health Care Education. Oxford University Press. 2003; 18(2): 19116.

[31] Visser A, Deccache A, Bensing J. Patient education in Europe: united differences. Ireland, Elsevier Science publisher; 2001. 1-5 p.

[32] Clinical Innovation and Governance, Family and Community Services. Core Standards for Nurses who Support People with a Disability; Communication and Behaviour Support for Nurses Appraisal. 2014; 1-14.

[33] Chen G, Huang C, Yang Y, et al. Patient Perception of Understanding Health Education and Instructions have Moderating Effect on Glycemic Control. BMC Public Health. 2014; 14: 683 PMID:24996669. http://dx.doi.org/10.1186/1471-2458-1 $4-683$ 